\title{
The Role of Sedation and Pulse 0ximetry During Upper Gastrointestinal Endoscopy
}

\author{
Sharma SK, ${ }^{1}$ Maharjan DK, ${ }^{1}$ Thapa PB, ${ }^{1}$ Adhikari SB, ${ }^{1}$ Byenjankar B, ${ }^{1}$ Khadka S, ${ }^{1}$ Gurung R' \\ 'Department of Surgery, Kathmandu Medical College Teaching Hospital, Sinamangal, Kathmandu, Nepal
}

\begin{abstract}
Introduction: To determine the changes in oxygen saturation, blood pressure and pulse rate during endoscopic procedure and to evaluate - oesophagogastroduodenoscopy (OGD) related discomfort assessed by the patient.
\end{abstract}

Methods: It is observational case control study. Baseline pulse, blood pressure and oxygen saturation were monitored before procedure, at one minute of procedure, at five minute and soon after procedure. Patients were randomly selected according to lottery system (1: without sedation and 2: with sedation) and divided into two groups; without and with sedation. Before leaving department they were asked about level of discomfort during and after procedure.

Results: Patient's mean age \pm SD: $36.65, \pm 11.42$ years and $53.3 \%$ were men. Base line mean oxygen saturation among sedated patient were $96.77 \pm 1.56 \%$ and $97.23, \pm 2.26 \%$ respectively $(\mathrm{P}=0.358)$. Mild to moderate hypoxia was noted more in sedated patient than in non sedated patient. Severe hypoxia was noted in $3.3 \%$ of sedated patient. No statistically significant change was noticed in pulse and blood pressure in both the group. None or only slight discomfort was experienced by $9.4 \%$ in non sedated group and $90.6 \%$ in sedated group. Severe discomfort by $96.4 \%$ in non sedated group and $3.6 \%$ in sedated group .

Conclusions: There is slight more incidence of mild hypoxia in sedated group than in non sedated group but no change in pulse and blood pressure. However, sedated patient have significant less level of discomfort than in non sedated group. Though routine use of pulse oxymeter is not necessary, routine use of sedation during endoscopy is recommended.

Key Words: discomfort, gastroscopy, oxygen saturation, pulse oximeter

\section{INTRODUCTION}

Upper gastrointestinal endoscopy is one of the commonest day care based procedure done throughout the world. Since its evolution from rigid oesophagoscopy to fibre optic flexible endoscopy to newer generation thin endoscopes, practice for anesthesia has also evolved from general anesthesia to sedation to local anesthaesia.Due to vast difference in patient's response to surgical procedure, guidelines for conscious sedation and monitoring have been established. ${ }^{1-3}$ Though it is often considered to be unpleasant, a number of centre in developed and developing countries perform the procedure without sedation. ${ }^{4-7}$ And irrespective of

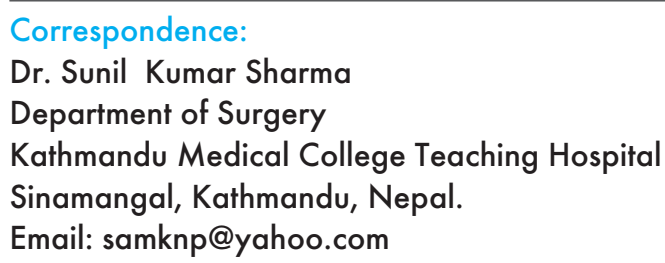


sedation, randomized control trial have shown that hypoxia is a common problem during OGD and sedation significantly increases the incidence of hypoxia, thus requiring further monitoring and intervention, if required..$^{8-10}$ However, procedure is associated with substantial pre-procedural anxiety and procedure related discomfort despite a low rate of medical complications and endoscopist tend to underestimate patient's level of discomfort. ${ }^{11}$

So the objectives of this study are to determine changes in oxygen saturation, blood pressure and pulses rate during endoscopic procedure and to evaluate upper GI endoscopy related discomfort assessed by patient among sedated and non sedated group.

\section{METHODS}

A prospective observational case control study was conducted in endoscopy unit of department of General Surgery, Kathmandu Medical College teaching hospital from July 1, 2008 to August 1, 2008. Approval from ethical committee was taken.

All patient who came for OGD after taking informed consent was evaluated according to ASA grading and patient were allotted according to lottery system into two groups, with sedation and without sedation.

All patients above 15 years and ASA I and II while exclusion criteria were ASA III and IV and all emergency including therapeutic procedure were included. Group A - patient who came to endoscopy unit after overnight fasting was taken and informed consent and Lignocaine Spray 100mg (Xylocaine, Astra Pharmaceuticals, and King Langley UK) to the pharyngeal area and total anesthesia was judged by absence of gag reflex.

Group B - Injection midazolam was administered at initial dose of $0.01 \mathrm{mg}$ through intravenous route and post procedure were kept in the ward for 1 hour for observation. Prior to procedure, baseline pulse rate, blood pressure oxygen saturation was monitored followed by continuous monitoring at 1 minute, 5 minute and immediate after procedure using Necloor Pulse oxymeter.

Before leaving department, both the group was asked about level of discomfort during procedure which was graded into no discomfort, minimal, moderate and severe discomfort.

Difference between mean and proportion were assessed using Man whitey test for non parametric data and Chi -Square test was used for nominal data by using 13.0 version of SPSS for windows software package for windows.

\section{RESULTS}

Total 100 patients underwent upper gastrointestinal endoscopy in 1 month (Table 1). Mean age group was 36.65 years $\pm 11.42(S D)$ with $53.3 \%$ male.

A change in the oxygen saturation at different stages of endoscopy was noted (Figure 1). There were no significant changes in pulse rate among two groups (Table 2). However, mild to moderate hypoxia was noted more in sedated patient than in non sedated patient and significant hypoxia was noted in $3.3 \%$ of sedated patient.

No statistically significant change was noticed in pulse and blood pressure in both the group (Figure 3-5 and Table 2-4). However, none or only slight discomfort was experienced by $9.4 \%$ in non sedated group and $90.6 \%$ in sedated group ( $p$ value -0.00 ) whereas severe discomfort was experienced by $96.4 \%$ in non sedated group and $3.6 \%$ in sedated group ( $p$ value -0.00 )

\section{DISCUSSION}

Upper gastrointestinal endoscopy has been used as one of the most frequently used diagnostic tool as a day care service. Though the complication rate has been very low during diagnostic endoscopy, it is not free from mortality. ${ }^{12}$ Moreover, procedure related discomfort and anxiety is yet another factor which is underestimated by endoscopists while doing unsedated endoscopy. In most of developed countries after development of guidelines more number of patients undergo diagnostic gastroscopies with so called conscious sedation. ${ }^{13}$ Main objective of sedation during procedure are to relieve patient anxiety and discomfort and improve quality of examination.

Studies have demonstrated episodes of significant hypoxia and arrhythmias occur during upper gastrointestinal endoscopy with or without sedation, ${ }^{14}$ however exact cause for it is not know though many reasons have been coined for it like age, size of endoscopy, endoscopist experience. ${ }^{15-18}$ According to Murray et $\mathrm{al}^{19}$ there is rise in pulse rate and systolic blood pressure after insertion of endoscope significantly, however study done by Shahzad et al, ${ }^{20}$ found no change in pulse rate and blood pressure during unsedated upper gastrointestinal endoscopy. Similarly in our study there was no statistically significant difference in pulse rate and blood pressure both systolic and diastolic between pre procedure, intraprocedure and post procedure.

Though many study have noticed hypoxemia during procedure, in our study as well no significant difference in oxygen saturation pre procedural, intra and post procedural. However mild to moderate hypoxia was noticed more in non sedated group and two patients in sedated group $(3.33 \%)$ had significant hypoxia. 
Sharma et al. The Role of Sedation and Pulse Oximetry During Upper Gastrointestinal Endoscopy

Table 1. Difference in oxygen saturation level means at different stages of procedure

\begin{tabular}{|c|c|c|c|c|}
\hline \multicolumn{2}{|c|}{ Injection midazolam } & \multirow{2}{*}{$\frac{\mathbf{N}}{30}$} & \multirow{2}{*}{$\begin{array}{l}\text { Mean Rank } \\
26.8\end{array}$} & \multirow[t]{2}{*}{$P$ value } \\
\hline \multirow{3}{*}{$\begin{array}{l}\text { Oxygen } \\
\text { saturation before } \\
\text { procedure }\end{array}$} & no & & & \\
\hline & yes & 30 & 34.1 & \multirow[t]{2}{*}{0.98} \\
\hline & Total & 60 & & \\
\hline \multirow{3}{*}{$\begin{array}{l}\text { Oxygen } \\
\text { Saturation in } 5 \text { in } \\
1 \mathrm{~min}\end{array}$} & no & 30 & 32.58 & \multirow{3}{*}{0.346} \\
\hline & yes & 30 & 28.42 & \\
\hline & Total & 60 & & \\
\hline \multirow{3}{*}{$\begin{array}{l}\text { Oxygen } \\
\text { Saturation in } 5 \text { in } \\
1 \mathrm{~min}\end{array}$} & no & 30 & 28.60 & \multirow{3}{*}{0.391} \\
\hline & yes & 30 & 32.40 & \\
\hline & Total & 60 & & \\
\hline \multirow{3}{*}{$\begin{array}{l}\text { Oxygen } \\
\text { Saturation post } \\
\text { procedure }\end{array}$} & no & 30 & 28.97 & \multirow{3}{*}{0.490} \\
\hline & yes & 30 & 32.02 & \\
\hline & Total & 60 & & \\
\hline
\end{tabular}

Mann-Whitney Test
Table 3. Changes in systolic blood pressure during procedure

\begin{tabular}{lllll}
\hline \multicolumn{1}{l}{ Injection midazolam } & N & Mean Rank & P value \\
\hline & no & 30 & 29.47 & \\
$\begin{array}{l}\text { Systolic BP } \\
\text { before procedure }\end{array}$ & yes & 30 & 31.53 & 0.65 \\
& Total & 60 & & \\
& no & 30 & 31.17 & \\
Systolic BP at 1 & yes & 30 & 29.83 & 0.77 \\
minute & Total & 60 & & \\
& no & 30 & 33.08 & \\
Systolic BP at 5 & yes & 30 & 27.92 & 0.25 \\
minute & Total & 60 & & \\
& no & 30 & 30.98 & \\
\hline $\begin{array}{l}\text { Systolic BP post } \\
\text { procedure }\end{array}$ & yes & 30 & 30.02 & 0.83 \\
\hline & Total & 60 & & \\
\hline
\end{tabular}

Table 2. Showing no significant changes in pulse rate among two groups

\begin{tabular}{|c|c|c|c|c|}
\hline Injection midazolam & & $\mathbf{N}$ & Mean Rank & $P$ value \\
\hline \multirow{3}{*}{ pulse before procedure } & no & 30 & 28.47 & \\
\hline & yes & 30 & 32.53 & 0.367 \\
\hline & Total & 60 & & \\
\hline \multirow{3}{*}{ pulse in 1 minute } & no & 30 & 27.32 & \\
\hline & yes & 30 & 33.68 & 0.158 \\
\hline & Total & 60 & & \\
\hline \multirow{3}{*}{ pulse in 5 minute } & no & 30 & 26.85 & \\
\hline & yes & 30 & 34.15 & 0.105 \\
\hline & Total & 60 & & \\
\hline \multirow{3}{*}{ pulse post procedure } & no & 30 & 28.02 & \\
\hline & yes & 30 & 32.98 & 0.270 \\
\hline & Total & 60 & & \\
\hline
\end{tabular}


Table 4. Changes in diastolic blood pressure during procedure

\begin{tabular}{|c|c|c|c|c|}
\hline \multicolumn{2}{|c|}{ Injection midazolam } & \multirow{2}{*}{$\frac{\mathbf{N}}{30}$} & \multirow{2}{*}{$\frac{\text { Mean Rank }}{30.07}$} & \multirow{2}{*}{$\frac{P \text { value }}{0.85}$} \\
\hline Diastolic BP be- & no & & & \\
\hline \multirow{2}{*}{ fore procedure } & yes & 30 & 30.93 & \\
\hline & Total & 60 & & \\
\hline Diastolic BP at 1 & no & 30 & 30.08 & 0.85 \\
\hline \multirow{2}{*}{ minute } & yes & 30 & 30.92 & \\
\hline & Total & 60 & & \\
\hline Diastolic BP at 5 & no & 30 & 29.68 & 0.72 \\
\hline \multirow{2}{*}{ minute } & yes & 30 & 31.32 & \\
\hline & Total & 60 & & \\
\hline Diastolic BP post & no & 30 & 30.50 & 1.00 \\
\hline \multirow{2}{*}{ procedure } & yes & 30 & 30.50 & \\
\hline & Total & 60 & & \\
\hline
\end{tabular}

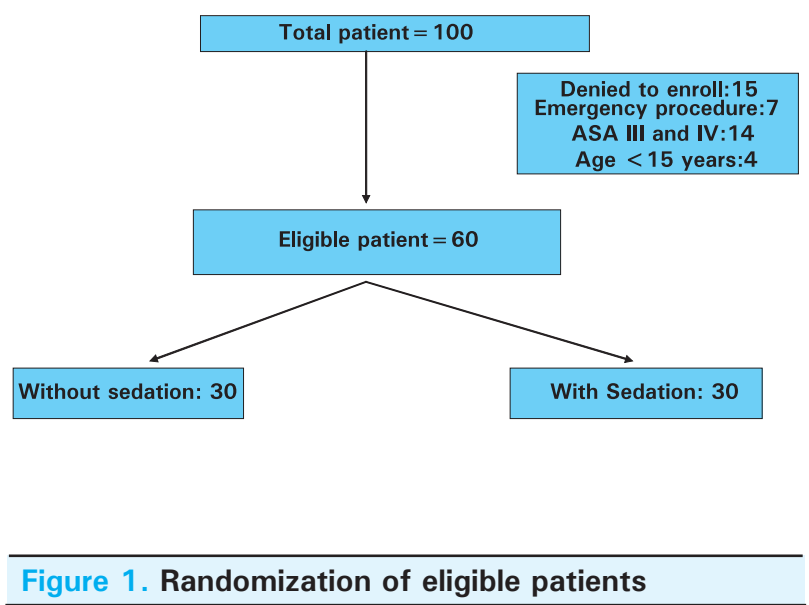

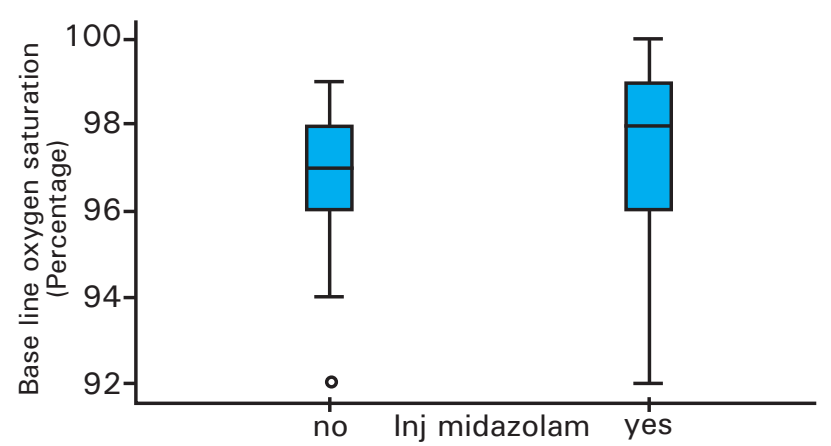
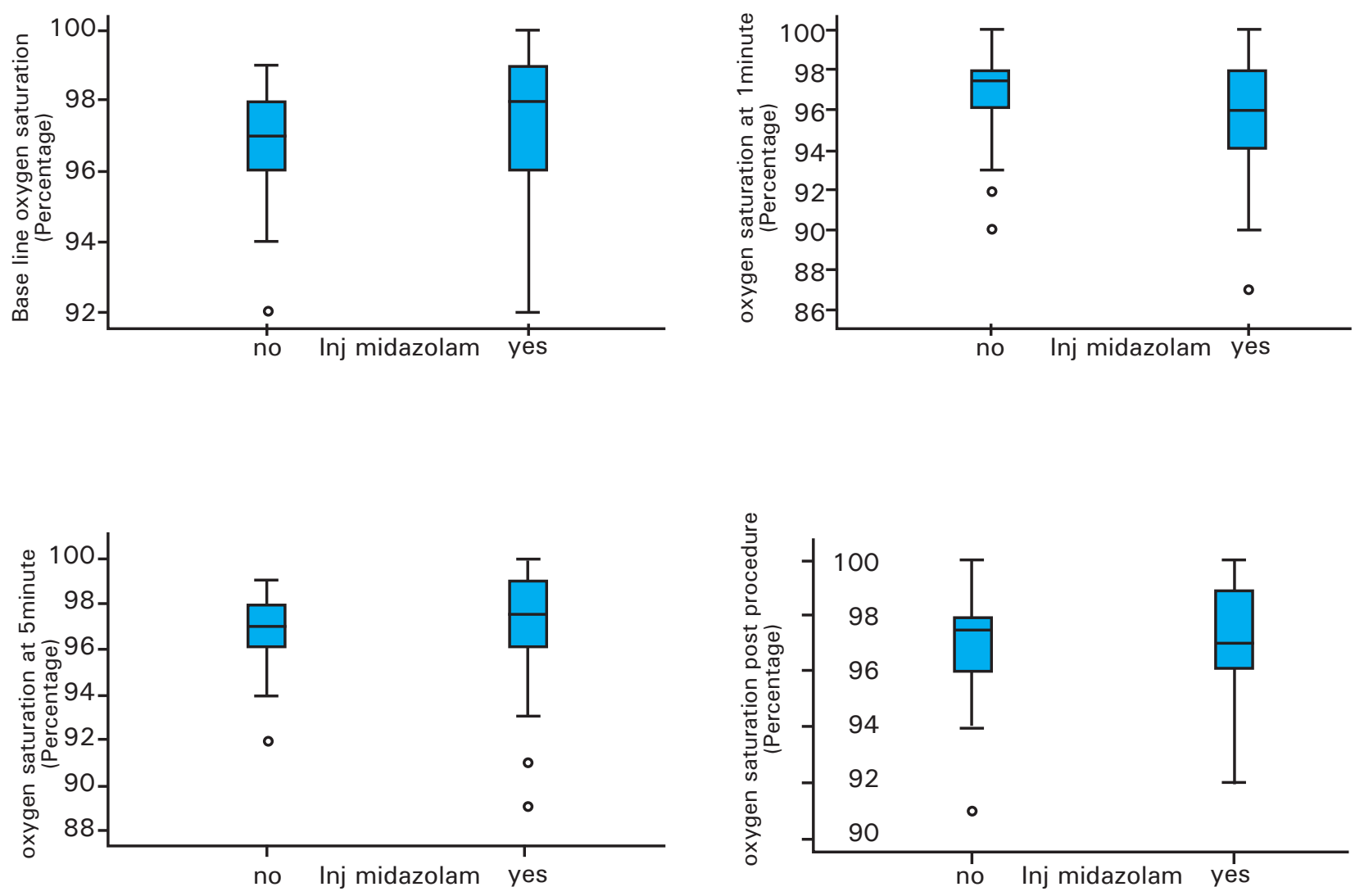

Figure 2. Changes in oxygen saturation between two groups at different stages of endoscopy 

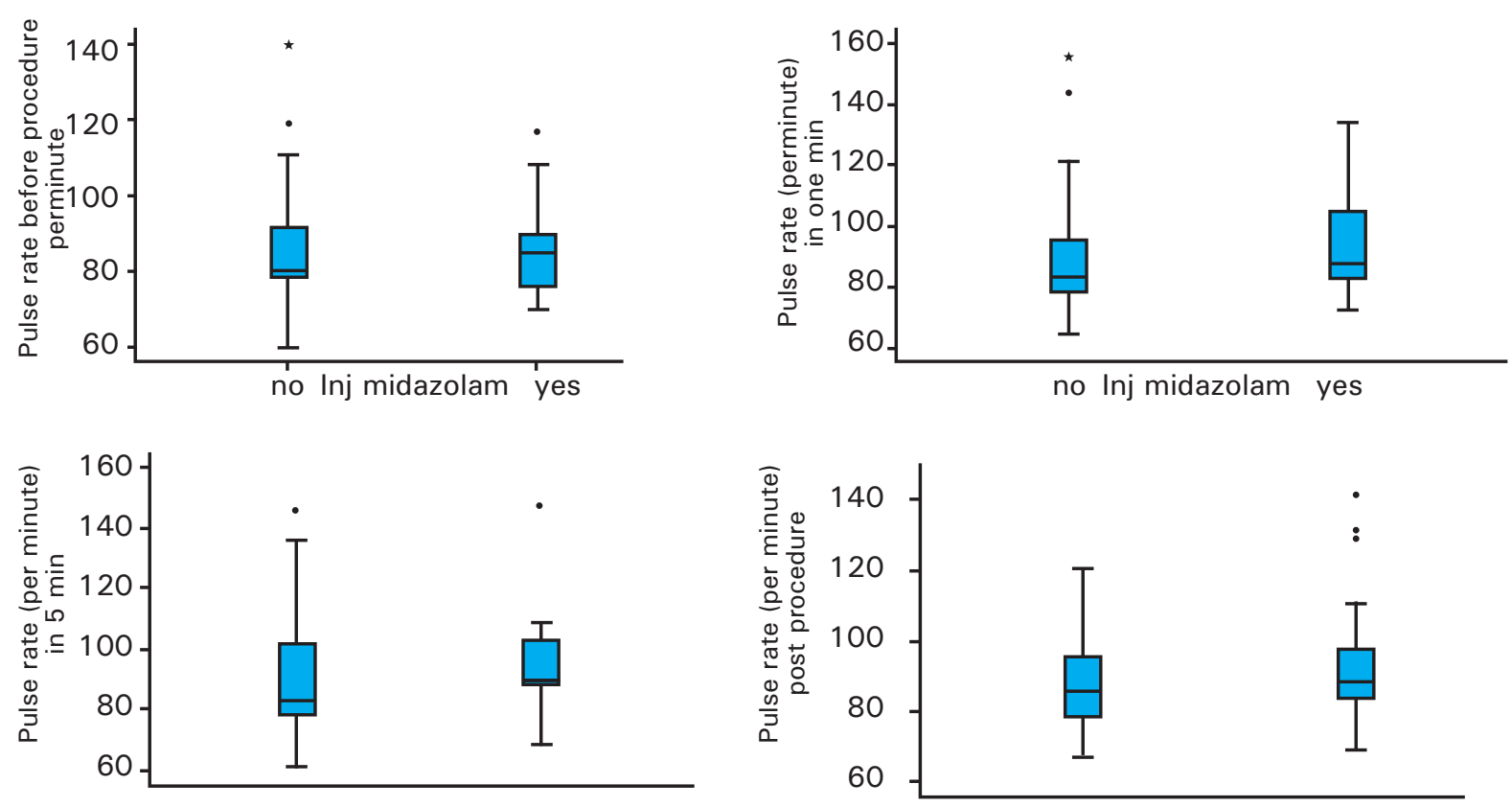

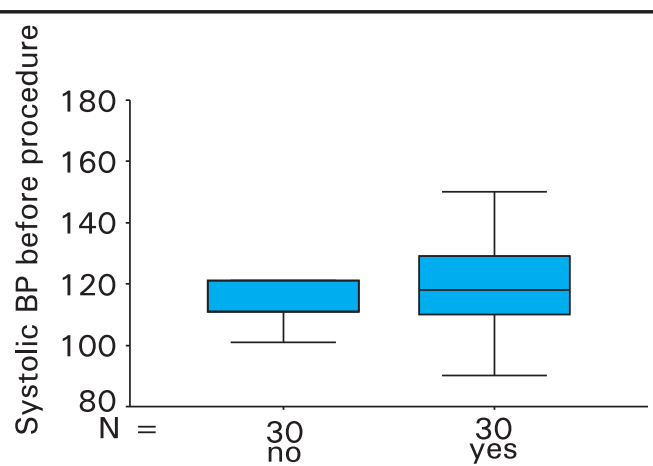

inj midazolam

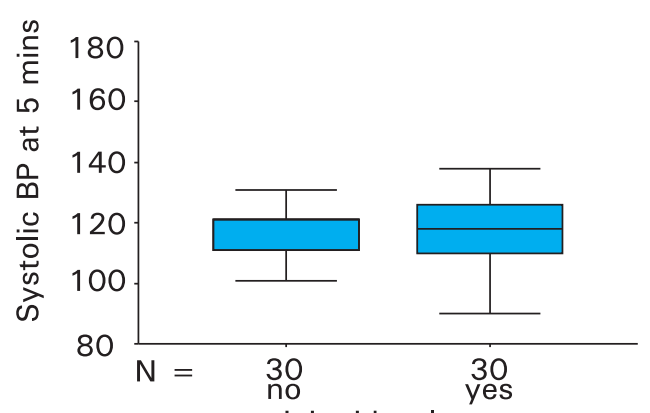

inj midazolam

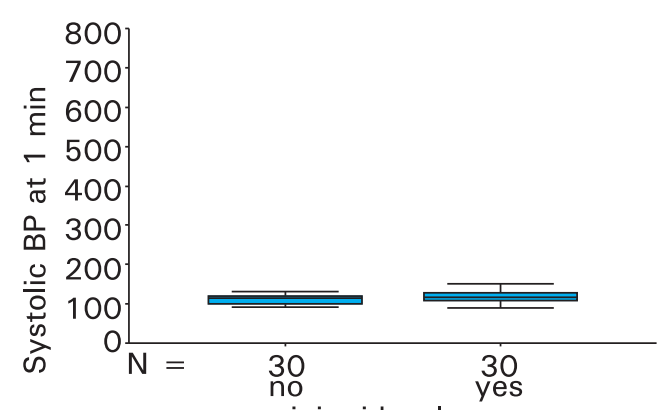

inj midazolam

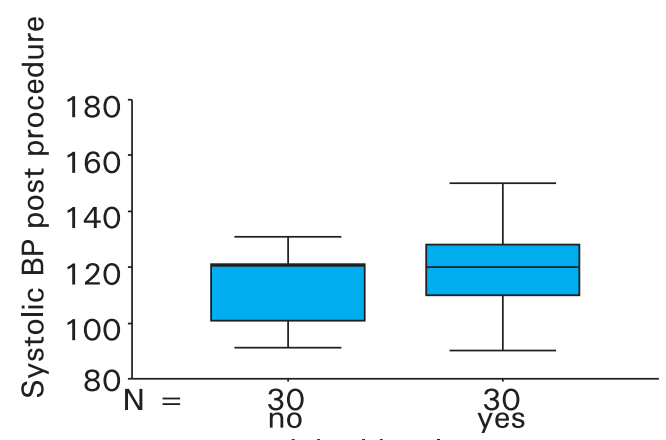

inj midazolam 
Change in Diastolic BP at different stages of procedure

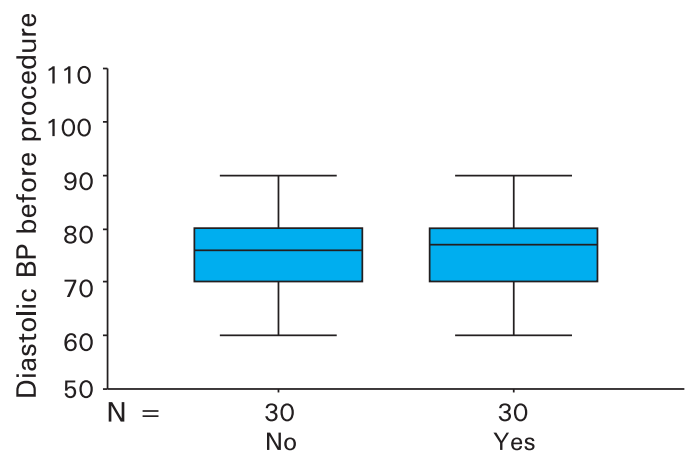

inj midazolam

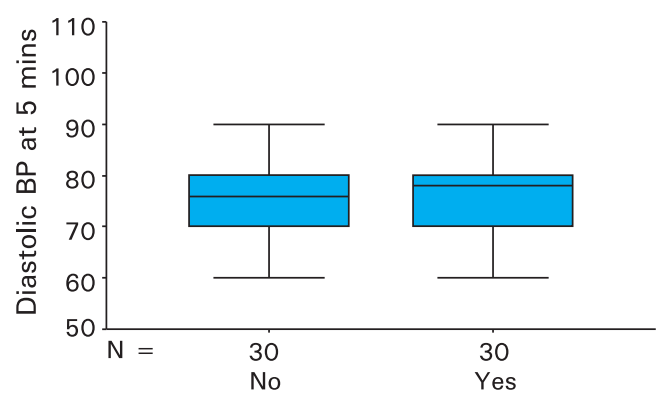

inj midazolam

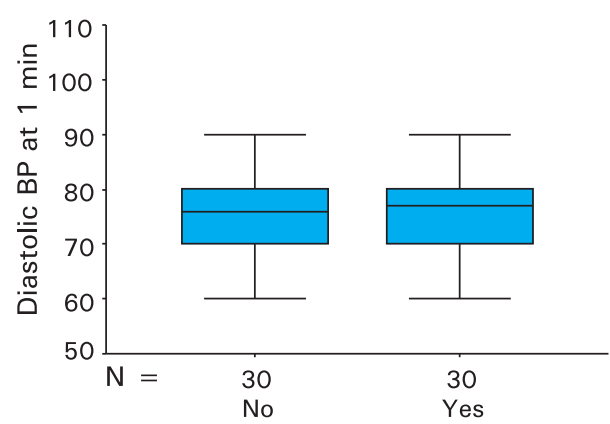

inj midazolam

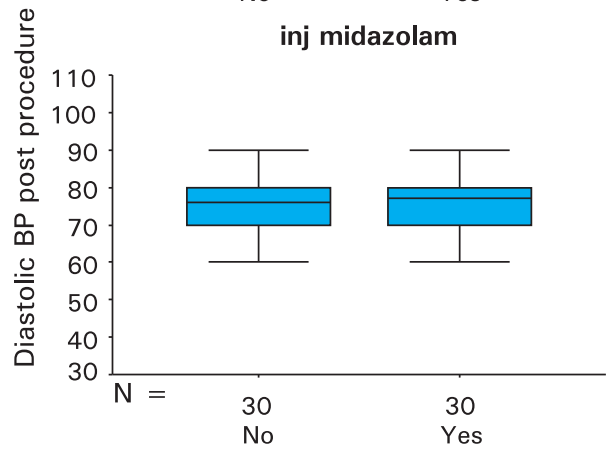

inj midazolam

Figure 5. Changes in diastolic blood pressure

Since every procedure intervening is associated with significant procedure induced anxiety and discomfort; however as an endoscopist we tend to underestimate patient feeling. In our study $90.6 \%$ of patient felt no or slight discomfort where as only $3.6 \%$ felt severe discomfort. Similar to our study Brigitte et al found that $68 \%$ of sedated patient felt none or slight discomfort while $14 \%$ felt severe discomfort. ${ }^{21}$

\section{CONCLUSIONS}

There is slight more incidence of mild hypoxia in sedated group than in non sedated group but no change in pulse and blood pressure. However, sedated patient have significant less level of discomfort than in non sedated group. Though routine use of pulse oxymeter is not necessary, routine use of sedation during endoscopy is recommended.

\section{REFERENCES}

1. Faigel DO, Baron TH, Goldstein JL, et al. Standards practice Committee, american society for gastrointestinal Endoscopy: guidelines for the use of deep sedation and anesthesia for GI endoscopy. Gastrointest Endosc. 2002;56:613-7.

2. Bell GD, McCloy RF, Charlton JE et al. Recommendations for standards of sedation and patient monitoring during gastrointestinal endoscopy. Gut. 1991;32:816-30.

3. Cohen LB, Delegge MH, AisenbergJ, etal. AGA institute review of endoscopic sedation. Gastroenterology. 2007;133:675-701.

4. Fisher NC, Bailey S, Gibson JA. A prospective, randomized controlled trial of sedation vs. no sedation in out-patient diagnostic upper gastrointestinal endoscopy. Endoscopy. 1998;30:17-25.

5. Abraham NS, Fallone CA, Mayrand S, Huang J, Wieczorek $\mathrm{P}$, Barkun AN. Sedation versus no sedation in the performance of diagnostic upper gastrointestinal endoscopy: a Canadian randomized controlled cost-outcome study. Am J Gastroenterol. 2004;99:1692-9.

6. Iwao T, Toyonaga A, Harada H, Harada K, Ban S, Ikegami $\mathrm{M}$, et al. Arterial oxygen desaturation during non-sedated diagnostic upper gastrointestinal endoscopy. Gastrointest Endosc. 1994;40:277-80.

7. Abraham N, Barkun A, Larocque M, Fallone C, Mayrand S, Baffis V, et al. Predicting which patients can undergo upper endoscopy comfortably without conscious sedation. Gastrointest Endosc. 2002 Aug;56(2):180-9.

8. Christopher P. Steffes, Choichi Sugawa, Robert F. Wilson, and Sharon R. Hayward .Oxygen saturation monitoring during endoscopy. Surg Endosc (1990) 4: 175-178.

9. Trevisani L, Sartori S, Gaudenzi P, Gilli G, Matarese G, Gullini $S$, et al. Upper gastrointestinal endoscopy: are preparatory 
interventions or conscious sedation effective? A randomized trial. World J Gastroenterol. 2004;10:3313-7.

10. Reed MWR, O'Leary DP, Duncan JL, Majeed AW, Wright B, Reilly CS. Effects of sedation and supplemental oxygen during upper alimentary tract endoscopy. Scand J Gastroenterol. 1993;28:297-341.

11. Hart R, Classen M. Complications of diagnostic gastrointestinal endoscopy. Endoscopy. 1990;22:196-262.

12. Lieberman DA, Wuerker CK, Katon RM. Cardiopulmonary risk of oesophagogastroduodenoscopy. Role of endoscope diameter and systemic sedation. Gastroenterology. 1985;88:396-540.

13. Waring JP, Baron TH, Hirota WK, et al. Guidelines for conscious sedation and monitoring during gastrointestinal endoscopy. Gastrointest Endosc. 2003;58:317-22.

14. Teague R. Guidelines on Safety and Sedation During Endoscopic Procedures.[online].2003 sep; Available from: URL:http://www.bsg.org.uk/clinical-guidelines/ endoscopy/guidelines-on-safety-and-sedation-duringendoscopic-procedures.html

15. Quine MA, Bell GD, McCloy RF, Charlton JE, Devlin HB, Hopkinsj A. Prospective audit of upper gastrointestinal endoscopy in two regions of England: safety, staffi ng and sedation methods. Gut. 1995;36:462-7.
16. Lavies NG, Creasy T, Harris K, Hanning CD. Arterial oxygen saturation during upper gastrointestinal endoscopy: infl uence of sedation and operator experience. Am J Gastroenterology. 1988;83:618-22.

17. Dhariwal A, Plevris JN, Finalyson NDC, Heading RC, Hayes PC. Age anemia and obesity-associated oxygen desaturation during upper gastrointestinal endoscopy. Gastrointest. Endosc 1992;38:684-8.

18. Patterson KW, Noonan N, Keeling NW, Kirkham R, Hogan DF. Hypoxemia during outpatient gastrointestinal endoscopy: the effects of sedation and supplemental oxygen. J Clin Anesth. 1995;7(2):136-40.

19. Murray AW, Morran CG, Kenny GNC, Macfarlane P, Anderson JR. Comparison of monitoring of arterial oxygen saturation, arterial pressure and the electrocardiogram Anaesthesia. 1991;46:181-4.

20. Sarwar S, Alam A, Khan AA. Pulse oximetry during gastrointestinal endoscopic procedures. J Coll Physicians Surg Pak. 2006 Feb;16(2):97-100.

21. Seip B, Huppertz-Hauss G, Sauar J, Bretthauer M, Hoff G. Patient's satisfaction: an important factor in quality control of gastroscopies. Scand J Gastroenterol. 2008,43:8,1004-11. 